\title{
Evaluation of Hydrophilic and Lipophilic Antioxidant Capacity in Spanish Tomato Paste: Usefulness of Front-Face Total Fluorescence Signal Combined with Parafac
}

\author{
Rosario Pardo-Botello ${ }^{1,2} \cdot$ Fátima Chamizo-Calero ${ }^{1} \cdot$ Olga Monago-Maraña $^{3} \cdot$ Raquel Rodríguez-Corchado $^{4}$. \\ Rosa de la Torre-Carreras ${ }^{4}$. Teresa Galeano-Díaz ${ }^{1,2}$
}

Received: 1 July 2021 / Accepted: 1 November 2021 / Published online: 1 December 2021

(C) The Author(s) 2021

\begin{abstract}
The hydrophilic and lipophilic antioxidant activities due to the main bioactive components present in Spanish tomato paste samples were studied, using standardized and fluorescent methods. After extraction, phenolic antioxidants (Folin-Ciocalteu method) and total antioxidant activity (TEAC assay) were evaluated, examining differences between hydrophilic and lipophilic extracts corresponding to different samples. Total fluorescence spectra of extracts (excitation-emission matrices, EEMs) were recorded in the front-face mode at two different ranges: $210-300 \mathrm{~nm} / 310-390 \mathrm{~nm}$, and 295-350 nm/380$480 \mathrm{~nm}$, for excitation and emission, respectively, in the hydrophilic extracts. In the lipophilic extracts, the first range was $230-283 \mathrm{~nm} / 290-340 \mathrm{~nm}$, while the second range was 315-383 $\mathrm{nm} / 390-500 \mathrm{~nm}$ for excitation and emission, respectively. EEMs from a set of 22 samples were analyzed by the second-order multivariate technique Parallel Factor Analysis (PARAFAC). Tentative assignation of the different components to the various fluorophores of tomato was tried, based on literature. Correlation between the antioxidant activity and score values retrieved for different components in PARAFAC model was obtained. The possibility of using EEMs-PARAFAC to evaluate antioxidant activity of hydrophilic and lipophilic compounds in these samples was examined, obtaining good results in accordance with the Folin-Ciocalteu and TEAC assays.
\end{abstract}

Keywords Tomatoes $\cdot$ Lipophilic and hydrophilic antioxidant activities $\cdot$ Folin-Ciocalteu and TEAC assays $\cdot$ Front-face fluorescence $\cdot$ Excitation-emission matrices-PARAFAC

\section{Introduction}

As part of Mediterranean diet, tomato is one of the most consumed vegetables in the world, as fresh fruits in salads, various culinary preparations, juices, or processed in the form of purees, concentrates, condiments, and sauces

Teresa Galeano-Díaz

tgaleano@unex.es

1 Departamento de Química Analítica, Universidad de Extremadura, Avenida de Elvas s/n, 06006 Badajoz, Spain

2 Instituto Universitario de Investigación del Agua, Cambio Climático Y Sostenibilidad, (IACYS), Facultad de Ciencias, Universidad de Extremadura, Avenida de Elvas s/n, 06006 Badajoz, Spain

3 Department of Analytical Sciences, National Distance Education University (UNED), 28040 Madrid, Spain

4 National Agro-Food Technology Center of Extremadura (CTAEX), 06195 Badajoz, Spain
(Mediterranean diet 2013). As been demonstrated in a great number of studies, Mediterranean diet presents health benefits (Sofi et al. 2010; Trichopoulou et al. 2014).

According to the FAO: "tomato is the second most important vegetable crop next to potato." According to the data recorded by this organization, the world production tomatoes has been 182.256.458 tons in 2018 (http://www.fao.org/faost at/en/\#data/QC/visualize), being Spain the seventh producer with 4,768,595.

The consideration of tomato as a functional food has been examined (Canene-Adams et al. 2005). Tomatoes are basically water and have a low caloric power given their low fat and dry matter content, sugars constitute the bulk of soluble solids. However, many tomato products are good sources of potassium and folate, similarly with other popular vegetables, and tomato products are a superior source of $\alpha$-tocopherol and vitamin C, whereas only carrots, between the other regularly consumed vegetables, are a better source of vitamin A than tomato-based foods. Also, tomatoes 
contain valuable phytochemicals, including carotenoids, mainly lycopene, $\beta$-carotene, phytoene, and phytofluene, and polyphenols as the conjugated forms of quercetin and kaempferol. Health effects derived from tomato components could also be due not only to these bioactive compounds but also to their metabolic products.

The antioxidant capacity of tomatoes can be mainly attributed to some of these nutrients, such us, lycopene, ascorbic acid, and phenolic compounds (Sahlin et al. 2004). These antioxidants compounds can be classified as hydrophilic or lipophilic, being differentiated the lipophilic (LAA) and hydrophilic antioxidant activity (HAA). Carotenoids, especially lycopene and $\beta$-carotene as well as vitamin E ( $\alpha$ - and $\gamma$-tocopherol) are the main lipophilic antioxidants, whereas in the hydrophilic fraction, polyphenolics (flavonoids - quercetin, kaempferol and naringenin, and phenolic acid-caffeic, chlorogenic, ferulic and p-coumaric acids), together with ascorbic acid can be found (Savatović et al. 2012).

Some of the factors influencing in the total amount of the antioxidant of tomato activities, such us, the different fractions of skin, pulp or seeds (Toor and Savage 2005), genotype of tomatoes (George et al. 2004), production and processing stages (Capanoglu et al. 2010; Gümüşay et al. 2015; Wu et al. 2004) and so on, have been examined in the case of processed foods from this vegetable. This way, different studies have been performed on the influence of the different stages of production of tomato paste over its content in some antioxidants (Capanoglu et al. 2008; Koh et al. 2012).

Due the great interest in these results, it is easily understood the needing for quick and easy analytical methods that allow the determination of each antioxidant compound, a set of them or the evaluation of HAA and LAA.

In the last case, different assays have been proposed based on different action modes: hydrogen atom transfer (HAT) and single electron transfer (SET) assays (Moharram and Youssef 2014). Thus, the modified method (Prior et al. 2003) using the ABTS (2,2'-azino bis (3-ethylbenzothiazoline6-sulfonic acid) diammonium salt) radical decolorization assay (Miller and Rice-Evans 1997) was used to separate the hydrophilic and lipophilic extracts of different finely ground freeze-dried fractions of tomatoes. In the assay for lipophilic and hydrophilic antioxidant capacities using the oxygen radical absorbance capacity $\left(\mathrm{ORAC}_{\mathrm{FL}}\right)$ with fluorescein as the fluorescent probe and 2,2'-azobis(2-amidinopropane) dihydrochloride as a peroxyl radical generator (Prior et al. 2003) on over 100 different kinds of foods, including fruits, vegetables (as tomatoes), nuts, dried fruits, spices, cereals, infant, and other foods, samples were initially extracted with 1:1 hexane/dichloromethane followed by acetone/water/acetic acid (70:29.5:0.5).

In another electron transfer-based method (Zanfini et al. 2017), fresh tomato sample was extracted with $\mathrm{CH}_{2} \mathrm{Cl}_{2}$ for the determination of lipophilic antioxidant activity (LAA). The residue was extracted with $60 \%$ methanol in water. In the assay proposed by (García-Alonso et al. 2015), tomato lipo- and hydrophilic extracts from a commercially available tomato concentrate were prepared extracting with hexane/ water $(25 / 2)$ or with water, respectively. In a revision of the methods available for the measurement of antioxidant capacity in foods and dietary supplements (Prior et al. 2005), a comparison of methods based upon factors as simplicity, instrumentation required, whether the assay is adaptable to measure HAA and LAA, between others, is included. The authors found that the ORAC method, based on HAT mechanism, and the Trolox equivalent antioxidant capacity (TEAC) assay, based on SET mechanism are the more adaptable to measure lipophilic and hydrophilic antioxidants.

On the other hand, it must be highlighted that hydrophilic AA measured by $\mathrm{ORAC}_{\mathrm{FL}}$ method has been found to be around ten times higher than lipophilic AA (Wu et al. 2004) and some compounds included in the hydrophilic extract are fluorescent.

These traditional assays are not the only utilized, but methods of antioxidant capacity evaluation include spectroscopy, chromatography and electrochemical techniques (Pisoschi et al. 2016; Pisoschi and Negulescu 2012). These alternative assays try to reduce the consumption of solvent and standards compared to the traditional assays, which are expensive, time-consuming, and laborious.

Nowadays, fluorescence spectroscopy is being of great interest for scientific community. Some reviews found in the literature show the use of fluorescence techniques in different kinds of foods (Hassoun et al. 2019; Lei and Sun 2019; Shaikh and O'Donnell 2017).

In the case of tomatoes samples, there are not many studies in the literature about the use of excitation-emission fluorescence matrices (EEMs) in combination with multivariate modeling to extract relevant information. The study performed by Orzel et al. focused in the use of excitation-emission fluorescence obtained from tomato pastes and water extracts of them for the evaluation of their hydrophilic antioxidant properties (Orzel et al. 2015). These signals, as well as IR spectra, were analyzed with chemometrics tools, as partial least-squares regression (PLSR) and its $\mathrm{N}$-way variant, to predict the total antioxidant capacity (TAC) or total phenolic content (TPC) of the samples, estimated by ORAC assay and the Folin-Ciocalteu $(\mathrm{F}-\mathrm{C})$ reagent, respectively. A PLSR model was built using a set of a few new variables that maximize the covariance between the dependent variable (TAC or TPC) and the explanatory variables (e.g., a collection of spectra). These explanatory variables can be arranged in a matrix form whether they represent a simple IR or UV-vis spectra or unfolded EEMs. The N-way partial least-squares regression can be regarded as an extension of two-way PLSR to model three-or higher-way data. 
The aim of this work was to explore the possibilities of using total fluorescence signals to evaluate the antioxidant activity of tomato paste, as an alternative to the established methods which are, in general, tedious and, time and reagents consuming. Specifically, the use of excitation-emission fluorescence matrices (EEMs) to examine different extracts from these samples, which correspond to hydrophilic and lipophilic antioxidant activity. This would allow us to investigate the nature of fluorescent compounds presents in these extracts of tomato paste, by previously constructing a parallel factor analysis (PARAFAC) model to distinguish between the possible components in these signals, and the analysis of the extracts using standardized methods, as the FolinCiocalteu and TEAC assays.

\section{Materials and Methods}

\section{Chemicals and Standards}

Acetone, acetic acid, sodium carbonate anhydrous, FolinCiocalteu reagent, and ethanol were purchased from Panreac (Barcelona, Spain), while isohexane was provided by VWR Chemicals (Barcelona, Spain) and potassium persulfate from Probus (Barcelona, Spain). Gallic acid, ABTS (2`2-azinobis [3-ethylbenzothiazoline-6-sulfonic] acid) and Trolox (6 hydroxy-2,5,7,8-trimethyl-chroman-2-carboxylic acid) were obtained from Sigma-Aldrich Química (Madrid, Spain).
$\mathrm{ABTS}^{\bullet+}$ radical was prepared by adding of $\mathrm{K}_{2} \mathrm{~S}_{2} \mathrm{O}_{8}(88 \mu \mathrm{L})$ to ABTS solution $(7 \mathrm{mM}, 25 \mathrm{~mL})$, storing at low temperature in the dark. For all preparations Milli-Q water, obtained by MilliQ-Water system (Millipore S.A.S, Francia), was used.

\section{Samples}

Samples of tomato paste (a total of 22) were obtained from Centro Tecnológico Nacional Agroalimentario "Extremadura"-CTAEX. These were prepared from tomatoes from different producers in Extremadura, Spain (characteristics in Table S1), submitted to different treatments until obtaining the tomato paste, as seen in the preparation process shown in Fig. 1. These tomatoes were subjected to "Hot-Break" enzymatic inactivation after previous processes of washing, selection, and cutting of the raw material. Skins and seeds were removed by sifter and refiners to finally obtain the tomato concentrate after the evaporation and pasteurization processes. These tomato pastes were stored frozen until preparation of the extracts to prevent their degradation.

\section{Extraction Process for Separation of Hydrophilic and Lipophilic Extracts}

All the samples were subjected to a pre-treatment with the aim to separate the hydrophilic and lipophilic components present in the tomato paste. A modified extraction method from Toor and Savage (2005) was used to separate the

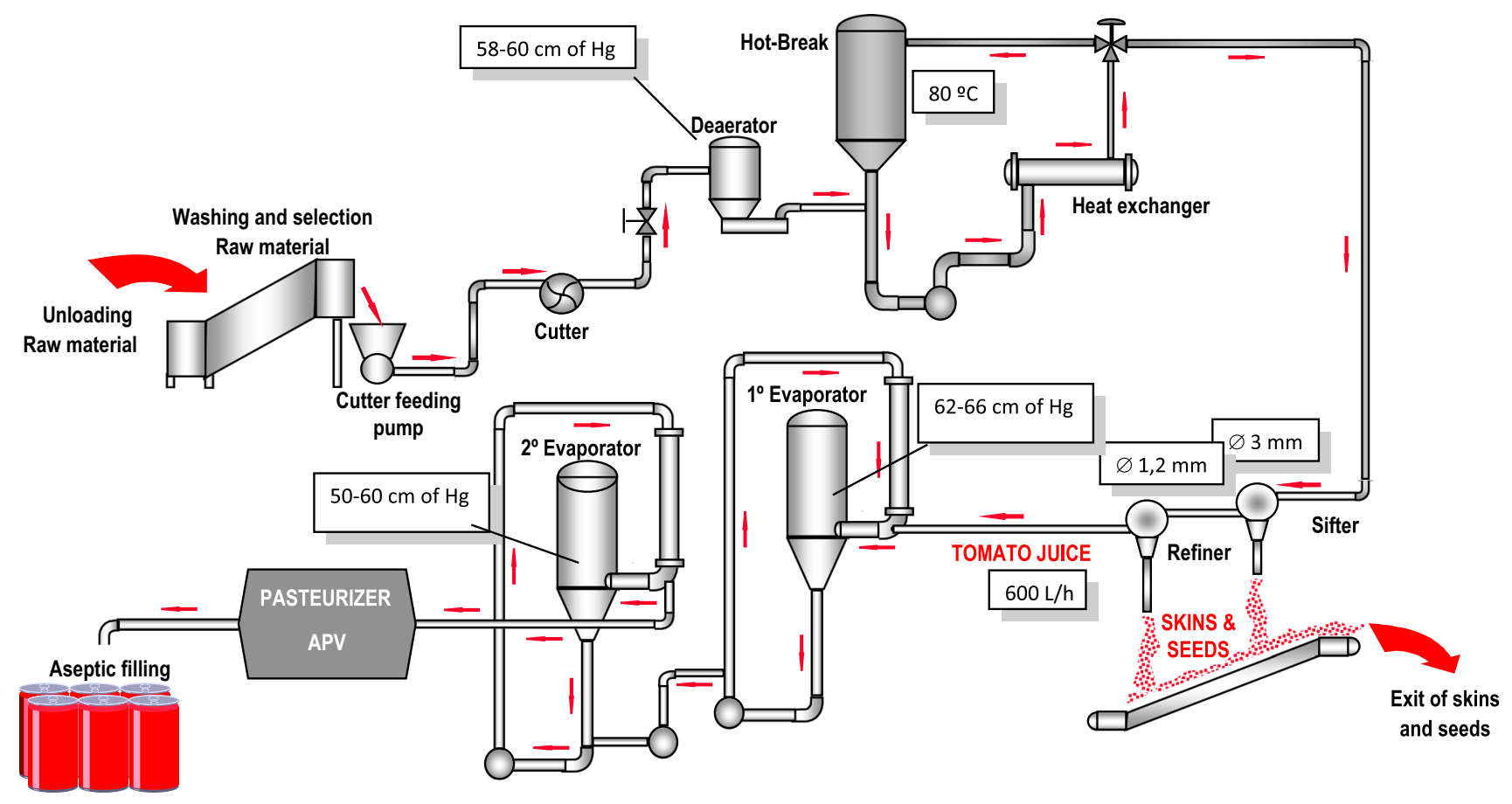

Fig. 1 Scheme for tomato paste preparation process 
hydrophilic and lipophilic fractions of the tomato paste. In brief, accurately weighed aliquots of $0.5 \mathrm{~g}$ of previously defrosted tomato paste were extracted twice with $10.0 \mathrm{~mL}$ of isohexane by shaking each time for $10 \mathrm{~min}$ in a vortex, followed by centrifugation at $3000 \mathrm{rpm}$ for $10 \mathrm{~min}$. The extracts were pooled, mixed well, and stored in 2 aliquots of $10.0 \mathrm{~mL}$ at low temperature.

Once the lipophilic fraction was separated, the solid residue was used for the extraction of the hydrophilic compounds, after drying under nitrogen flow to eliminate the remaining isohexane present. This residue was extracted with $10.0 \mathrm{~mL}$ of a mixture of acetone:water:acetic acid, (70:29.5:0.5) by shaking in a vortex and sonicated for $10 \mathrm{~min}$ to completely dissolve the hydrophilic components, followed by centrifugation at $3000 \mathrm{rpm}$ for $10 \mathrm{~min}$. The supernatant (hydrophilic extract) was then transferred to two tubes in 2 aliquots of $5.0 \mathrm{~mL}$ for their conservation at low temperature. In both extracts, the determination of polyphenolic compounds was carried out by the Folin-Ciocalteu method, and the antioxidant activity was studied by the TEAC assay.

On the other hand, the hydrophilic and lipophilic antioxidant activity of the different extracts from tomato paste was evaluated by front-face total fluorescence signal, obtaining the excitation-emission matrices (EEMs). The lipophilic EEMs were obtained directly from the same tomato lipophilic extract already obtained, without previous treatment of them. However, recording EEMs directly in hydrophilic gave bad results, due to the acetone absorbs all the incident radiation on the sample. For this reason, other hydrophilic extracts were prepared using Milli-Q water as extracting agent according to the slightly modified García-Alonso et al. method (2015), as follow: magnetic stirring of $1 \mathrm{~g}$ tomato paste in $10.0 \mathrm{~mL}$ distilled water for $7 \mathrm{~min}$. Then, the extract was filtered $0.2 \mu \mathrm{m}$ pore size syringe filter and stored at $-4{ }^{\circ} \mathrm{C}$ until analyzed.

\section{Folin-Ciocalteu Method}

Total antioxidant activity of the polyphenols in the hydrophilic and lipophilic extracts of the tomato fractions was measured by the method, adapted from Toor and Savage (2005), based on a redox reaction between polyphenols and a mixture of $\mathrm{Mo}(\mathrm{VI})$ and $\mathrm{W}(\mathrm{VI})$ in which lower oxidation states of these metals are obtained. Gallic acid was used as a standard, and the antioxidant activity were expressed as gallic acid equivalents (GAE) per $100 \mathrm{~g}$ of tomato paste.

The influence of gallic acid concentration was examined between $1.0 \mathrm{mg} / \mathrm{L}$ and $25.0 \mathrm{mg} / \mathrm{L}$ to find the linear interval of the calibration plot, and then standards between $2.52 \mathrm{mg} / \mathrm{L}$ and $15.20 \mathrm{mg} / \mathrm{L}$ were utilized to adjust the calibration parameters. The standards were prepared, in triplicate, in $25-\mathrm{mL}$ flasks, adding the corresponding volumes of gallic acid stock solution $(100.0$ or $1000.0 \mathrm{mg} / \mathrm{L})$. These volumes were diluted with $10 \mathrm{~mL}$ of $\mathrm{H}_{2} \mathrm{O}$ Milli-Q in $25.0 \mathrm{~mL}$ volumetric flask and then treated with $0.25 \mathrm{~mL}$ of the Folin-Ciocalteu reagent. These solutions were kept in the dark at room temperature for $10 \mathrm{~min}$, the time required to complete the oxidation reaction. Subsequently, the mixture was neutralized by adding $2.5 \mathrm{~mL}$ of $\mathrm{Na}_{2} \mathrm{CO}_{3}\left(7.5 \%\right.$ w/v) and diluted with $\mathrm{H}_{2} \mathrm{O}$ Milli-Q to the mark. The analytical signal (absorbance signal at $662 \mathrm{~nm}$ ) was taken $9 \mathrm{~h}$ after preparation of the samples.

When the Folin-Ciocalteu method was applied to hydrophilic extract, $1.5 \mathrm{~mL}$ of this was appropriately diluted with $10 \mathrm{~mL}$ of $\mathrm{H}_{2} \mathrm{O}$ Milli-Q in $25.0 \mathrm{~mL}$ volumetric flask, following as described above.

On the other hand, the lipophilic extract was prepared by drying a known volume $(1.5 \mathrm{~mL})$ of the isohexane extract under nitrogen flow directly in the flask. Subsequently, $2.0 \mathrm{~mL}$ of acetone and $\mathrm{H}_{2} \mathrm{O}$ are added until a volume of $10.0 \mathrm{~mL}$ to continue with the same procedure as in the hydrophilic extracts.

\section{TEAC Assay (Trolox Equivalent Antioxidant Capacity)}

The antioxidant activity of the hydrophilic and lipophilic extracts of the tomato fractions was measured using ABTS (2`2-azino-bis [3-ethylbenzothiazoline-6-sulfonic] acid) radical decolorization assay (Ramírez Anaya 2013). This method consists of an electron transfer reaction (SET), in which the ability of the sample to capture free radicals is measured by the spectrophotometric monitoring at $749 \mathrm{~nm}$ of the ABTS ${ }^{\bullet+}$ radical discoloration. Therefore, it is based on the ability of an antioxidant to stabilize the $\mathrm{ABTS}^{\bullet+}$ colored cation radical, inhibiting the chain reaction that leads to oxidation. The antioxidant activity was expressed as equivalents of Trolox ( $\mu \mathrm{mol}$ Trolox/g of sample).

The validation by the TEAC method, using Trolox as internal standard, was carried out by preparing in triplicate seven Trolox standards with concentrations between 0.025 and $0.50 \mathrm{mM}$. These standards were prepared in $10.0-\mathrm{mL}$ volumetric flasks, adding the corresponding volumes of the standard solution $(5.00 \mathrm{mM})$, and following the above-mentioned procedure. In brief, volumes of $150 \mu \mathrm{L}$ of the corresponding standard solution were mixed with $3 \mathrm{~mL}$ of the diluted $\mathrm{ABTS}^{\bullet+}$ solution and the absorption spectra (300-900 nm) of each of the standard solutions was recorded at the beginning and $30 \mathrm{~min}$ after starting the reaction, when the equilibrium state is reached, using ultrapure water to obtain the baseline. The absorbance value at $749 \mathrm{~nm}$ was measured at the beginning $\left(\mathrm{A}_{0}\right)$ and after reaching the equilibrium $\left(\mathrm{A}_{1}\right)$, and the $\mathrm{ABTS}^{\bullet+}$ radical elimination was obtained according to

\section{$A B T^{*+}$ radicalelimination $=(A 0-A 1) / A 0$}

The lipophilic and hydrophilic extracts of the tomato paste samples were also analyzed separately. In brief, 500 
$\mu \mathrm{L}$ of the liquid extract (mixture of acetone:water:acetic acid (70:29.5:0.5)) of the hydrophilic samples were dried under nitrogen flow to eliminate completely the acetone, and, subsequently, $100.0 \mu \mathrm{L}$ of ethanol and $3 \mathrm{~mL}$ of the diluted ethanol solution of the $\mathrm{ABTS}^{\bullet+}$ radical $(5: 100)$ were added to the aliquots of $50.0 \mu \mathrm{L}$ of the different samples. The discoloration due to the cation reduction reaction by the antioxidants in the sample was measured 30 min after the start. All assays have been carried out with ethanol, as the ABTS $^{\bullet+}$ radical and the polar antioxidants are soluble in this solvent (Romero et al. 2002).

The same procedure has been followed for the lipophilic extracts but, in this case, given the lower concentration of antioxidants, volumes of $3 \mathrm{~mL}$ of the diluted solution of $\mathrm{ABTS}^{\bullet+}$ radical were added to $150 \mu \mathrm{L}$ of the extracts, continuing as described above.

\section{Instrumentation and Software}

To obtain fluorescence EEMs, a Fluorescence Spectrophotometer Varian Model Cary connected to a PC microcomputer via an IEEE 488 (GPIB) serial interface Eclipse was employed, and the Cary Eclipse 1.0 software was used for data acquisitions. A $1.0-\mathrm{cm}$ quartz cell was used to carry out the measurements at front-face fluorescence mode, utilizing a variable-angle front-face accessory, looking for reflected light, scattered radiation, and depolarization phenomena were minimized. Angle of incidence, defined as the angle between the excitation beam and the perpendicular to the cell surface, was set at $34^{\circ}$. The slits of excitation and emission monochromators were set at $5 \mathrm{~nm}$. EEMs were collected obtaining successive emission spectra (with a resolution of $1 \mathrm{~nm}$ ), varying the excitation wavelength (with a resolution of $3 \mathrm{~nm}$ ). Two different ranges were recorded (Table 1).

The data were arranged in 3D array with dimensions MxNxP (samples $x$ number of wavelengths emission $\mathrm{x}$ number of wavelengths excitation) in order to apply Parallel Factor Analysis (PARAFAC) (Bro, 1997). PARAFAC was applied in Matlab (Matlab R2007b, version 7.5.0.342), using MVC2, a graphic interface available at http://www. iquir-conicet.gov.ar/descargas/mvc2.rar (Olivieri et al. 2009; Olivieri and Escandar 2014). To model the set of fluorescence data by PARAFAC, different number of components must be assayed and the optimum selected. Given that concentrations and spectral values are always positive, non-negative constraints for the resolved profiles for all modes were applied. ACOC program was used to obtain the figures of merit. (Espinosa-Mansilla et al. 2005).

\section{Results and Discussion}

As mentioned in the previous section, samples of tomato paste were obtained from tomatoes of different producers, and they were stored frozen until preparation of the extract to prevent their deterioration. All the samples were subjected to a pre-treatment with the aim to separate the hydrophilic and lipophilic components present in the tomato paste. In brief, hydrophilic and lipophilic extracts from 22 tomato paste samples were analysed, after validation of the spectrophotometric methods used.

\section{Measurement of the Antioxidant Activity in Hydrophilic and Lipophilic Extracts of Tomato Paste Samples}

For the determination of the antioxidant capacity in the different extracts of the tomato paste samples, gallic acid was used as standard for obtaining the calibration plot in the $\mathrm{F}-\mathrm{C}$ method and a hydrosoluble analogue of vitamin $\mathrm{C}$, Trolox, to carry out the TEAC assay (Pérez-Jiménez et al., 2008).

\section{Analysis of Samples Using the Folin-Ciocalteu Method}

Calibration results for the Folin-Ciocalteau method used in this study are shown in the supplementary information (Table S2). Reagents need to be added in the order mentioned in the "Materials and methods" section, for the redox reaction takes place with a color change from yellow to blue when the $\mathrm{pH}$ changes to basic medium. The absorption spectrum (400-800 $\mathrm{nm}$ ) of each of the standard solutions was recorded, showing a shift of $\lambda_{\max }$ to lower values as the gallic acid concentration increases (hypsochromic shift), although
Table 1 Instrumental conditions utilized in the recording EEMS

\begin{tabular}{lllll}
\hline & Excitation $(\mathrm{nm})(3 \mathrm{~nm}$ steps $)$ & Emission $(\mathrm{nm})(1 \mathrm{~nm}$ steps $)$ & Slit (nm) & Voltage $(\mathrm{V})$ \\
\hline Hydrophilic extracts & & 5 & 630 \\
Range 1 & $210-300$ & $310-390$ & 5 & 630 \\
Range 2 & $295-350$ & $380-480$ & & \\
Lipophilic extracts & & 5 & 630 \\
Range 1 & $230-283$ & $290-340$ & 5 & 630 \\
Range 2 & $315-385$ & $390-500$ & 5 \\
\hline
\end{tabular}


the absorption band is so broad that this does not implies error. Finally, the absorbance was measured at $662 \mathrm{~nm}$. The stability of the signal was examined, during $48 \mathrm{~h}$ in which samples were kept in darkness, concluding that it can be taken $9 \mathrm{~h}$ after preparation of the samples.

The 22 samples of hydrophilic and lipophilic extracts were analyzed following this procedure. These results were expressed in mg GAE/100 g of tomato paste and are shown in Table S4 for the hydrophilic extracts and in Table S5 for the lipophilic ones.

The results obtained for hydrophilic and lipophilic extracts from tomato paste showed no very different values among the samples. Figure $2 \mathrm{~A}$ and $\mathrm{B}$ shows the total polyphenol for hydrophilic and lipophilic extracts, respectively. In hydrophilic extracts (Fig. 2A) ranges were from 273.9 to $173.4 \mathrm{mg} \mathrm{GAE} / 100 \mathrm{~g}$, being the sample T.85 with the highest level of total polyphenols and T.78 the lowest. However, in lipophilic samples (Fig. 2B) the value ranges between 76.8 and $38.2 \mathrm{mg} \mathrm{GAE} / 100 \mathrm{~g}$, being the maximum value for sample T.76 and the minimum for T.103. No correlation has been found between polyphenols content in the hydrophilic and lipophilic extracts of the different samples. The values of total polyphenols by the Folin-Ciocalteu method are much higher in hydrophilic extracts than in lipophilic extracts, due to the higher solubility of polyphenolic compounds in a polar environment (acetone: water: acetic
Fig. 2 Total polyphenols content for each sample, expressed in $\mathrm{mg}$ GAE/100 $\mathrm{g}$ of tomato paste in the hydrophilic (A) and lipophilic (B) extracts
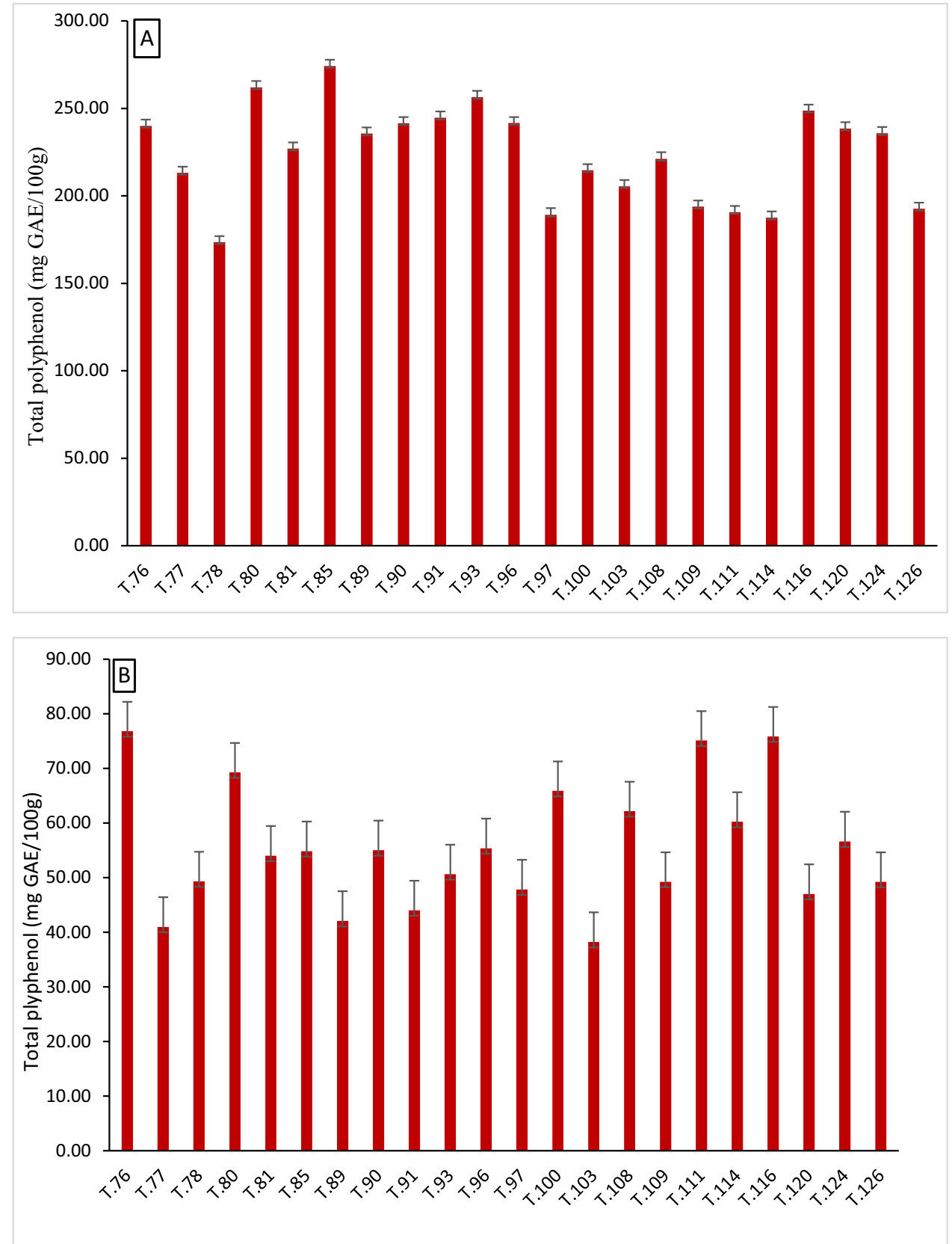
acid) as compared with non-polar one (isohexane). On the other hand, carotenoid compounds were found mainly in lipophilic extracts. Other authors studied the content of total polyphenols without considering the different hydrophilic and lipophilic extracts, obtaining very low values of the amount of total polyphenols (Vallverdú-Queralt et al. 2011; Wu et al. 2004). Toor and Savage (2005), studied both fractions classifying the content according to the different parts present in tomato, showing lower values of the amount of total polyphenols than those obtained in tomato paste sample. The main difference between both types of samples is the amount of water present, with a lower amount in the tomato paste, which implies a higher concentration of the rest of the components.

\section{Analysis of Samples Using the TEAC Assay}

Calibration results for this method are shown in the Table S3. The 22 tomato pastes were analyzed following the procedure described in the Materials and methods section. The results of antioxidant activity were calculated through the Trolox calibration plot, using the absorbance as analytical signal expressed as parts per unit of $\mathrm{ABTS}^{\bullet+}$ radical elimination. These results are presented in Fig. $3 \mathrm{~A}$ and B for the hydrophilic and lipophilic extracts, respectively. The antioxidant activity in hydrophilic extracts ranges from 61.1 to $13.7 \mu \mathrm{mol}$ Trolox/g, showing the highest antioxidant activity for the sample T.124 and the lowest for T.108 (Table S6). However, in lipophilic samples (Fig. 3B) the value ranges between 97.00 and $9.30 \mu \mathrm{mol}$ Trolox/g, being the maximum value for the sample T.126 and T.77 the
Fig. 3 Antioxidant activity for each sample (TEAC assay), expressed in $\mu \mathrm{mol}$ Trolox/g of tomato paste in the hydrophilic (A) and lipophilic (B) extracts
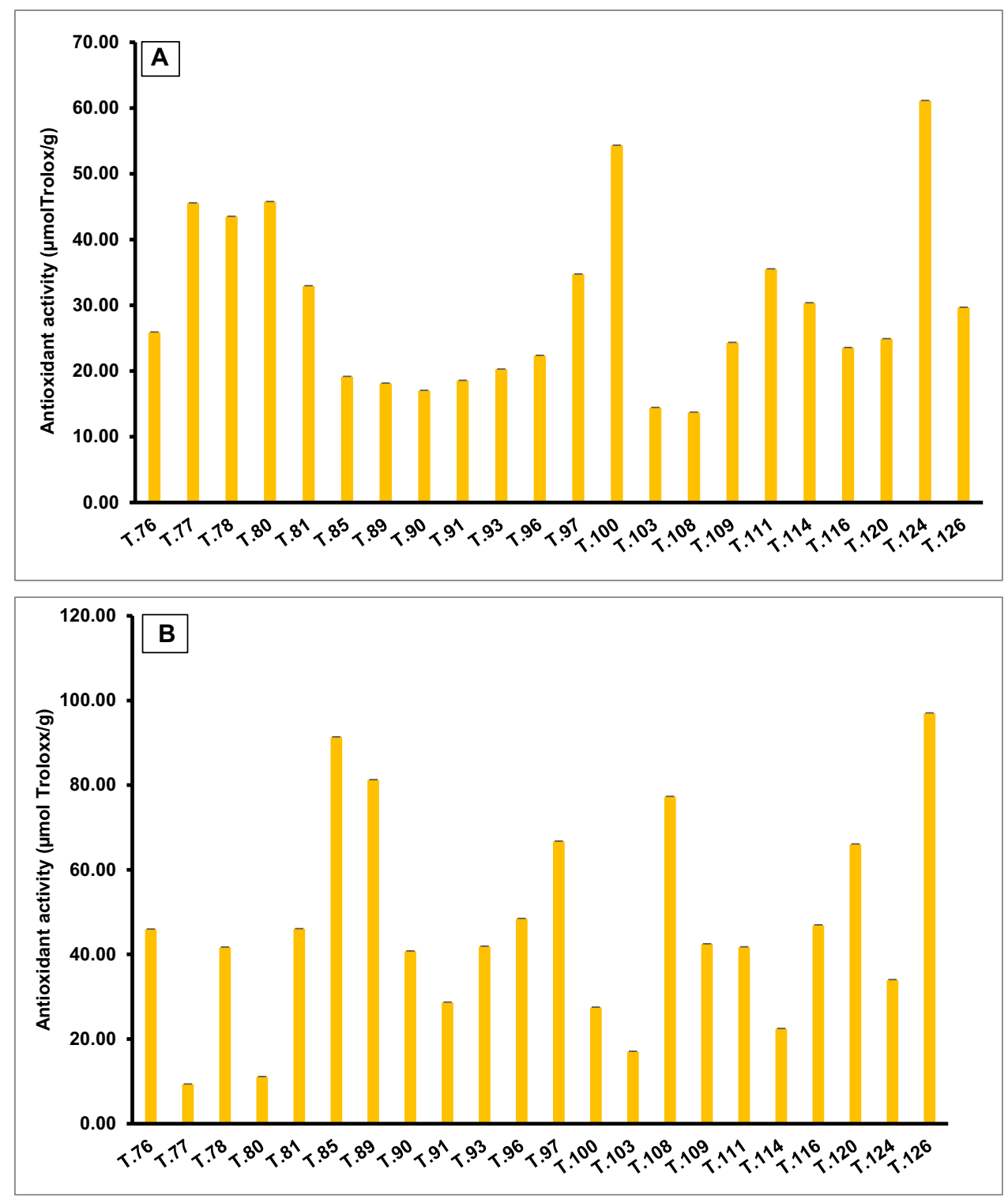
minimum (Table S7). It is remarkable that these results show greater dispersion that those of polyphenols content. Also, it can be highlighted that, in some samples, the antioxidant activity is higher in lipophilic extracts from tomato paste samples. These results did not correspond to those observed by other authors, who determined the antioxidant capacity of different varieties of tomato (MartínezValverde et al. 2002), being the pear tomato one of the most studied. Zanfini et al. (2017) studied the antioxidant activity of total hydrophilic (HAA) and lipophilic (LAA) of different pear tomatoes (red, yellow, pale yellow and black tomato fruits), observing that HAA was higher than LAA and that the Shiren type tomatoes (red), with a high carotenoid and total phenolic contents, showed the highest antioxidant activity. Vallverdú-Queralt et al. (2011) only analyzed the antioxidant activity in hydrophilic extracts of crushed tomato samples. Toor and Savage (2005) determined such activity in both extracts for the different parts of the fruit (seed, pulp and skin), ranging in hydrophilic extracts from 0.82 to $1.14 \mu \mathrm{mol}$ Trolox/g and from 0.07 to $0.19 \mathrm{mg} \mu \mathrm{mol}$ Trolox $/ \mathrm{g}$ for lipophilic extracts. Also, different studies have been performed on tomato paste samples. Hence, Capanoglu et al. (2008) applied different assays to evaluate hydrophilic and lipophilic antioxidant activities in samples taken from various tomato processing steps, and they found that the TEAC method gives considerably higher values of antioxidant activity in hydrophilic than in lipophilic extract. Koh et al. (2012) also examined the influence of processing on the content of the different antioxidants and found that, in general, this diminish when fresh tomatoes are processed to tomato pastes, being flavonoids contents lower than lipophilic antioxidants (carotene and lycopene) in these last, although ascorbic acid continues being the most abundant of the examined antioxidants. Our results could indicate that the contribution of ascorbic acid to the antioxidant activity of the hydrophilic extracts obtained as described, calculated by the TEAC method applied according to the procedure above detailed, could be low. In these cases, the antioxidant activities of lipophilic extracts, due to carotenoids could be higher than HAA, due to polyphenols, antioxidants mainly present in the hydrophilic extracts (Martí 2018). Nevertheless, the influence of different other factors, such as the preparation of the sample, as well as the origin and variety of the fruit, have to be also in consideration (Lenucci et al. 2006). For example, Jacob et al (2010) found that the effects of thermal processing on the nutritional value of tomato paste differ according to the extension of heating, leading to an enhancement of the phenolic antioxidants of tomatoes, which are responsible for maintaining the antioxidant capacity of processed products after losses of ascorbic acid.

\section{Evaluation of Hydrophilic and Lipophilic Antioxidants of Tomato Paste by Total Fluorescence Combined with PARAFAC}

To explore the possibility of using fluorescence spectroscopy as tool to evaluate phenolic antioxidants and total activity, different experiments were assayed. Firstly, front-face fluorescence was selected to collect the excitation-emission matrices (EEMs) due to the inner-filter effect decreases as compared with conventional fluorescence. Also, the best ranges for each kind of extract were selected and they are shown in Table 1.

After that, tomato lipophilic extracts were evaluated. Samples were prepared as detailed in the Materials and methods section and EEMs were obtained in the two different ranges. Figure 4 shows contour plots corresponding to the EEMs for one lipophilic tomato paste extract. As observed, both regions are quite different. Range 1 shows a wide band and maxima signal at wide band from 280 to $315 \mathrm{~nm}$ for emission and from 250 to $280 \mathrm{~nm}$ for excitation. This region might be related with the anthocyanins and other polyphenols compounds (Lai et al. 2007). Range 2 shows maxima better defined and the fluorescent intensity for this range is higher as well. In this case, maxima for excitation
Fig. 4 EEMs of a lipophilic extract in the two different ranges examined. Range 1 (left): excitation from 230 to $283 \mathrm{~nm}$ and emission from 290 to $340 \mathrm{~nm}$ and range 2 (right): excitation from 315 to $383 \mathrm{~nm}$ and emission from 390 to $500 \mathrm{~nm}$
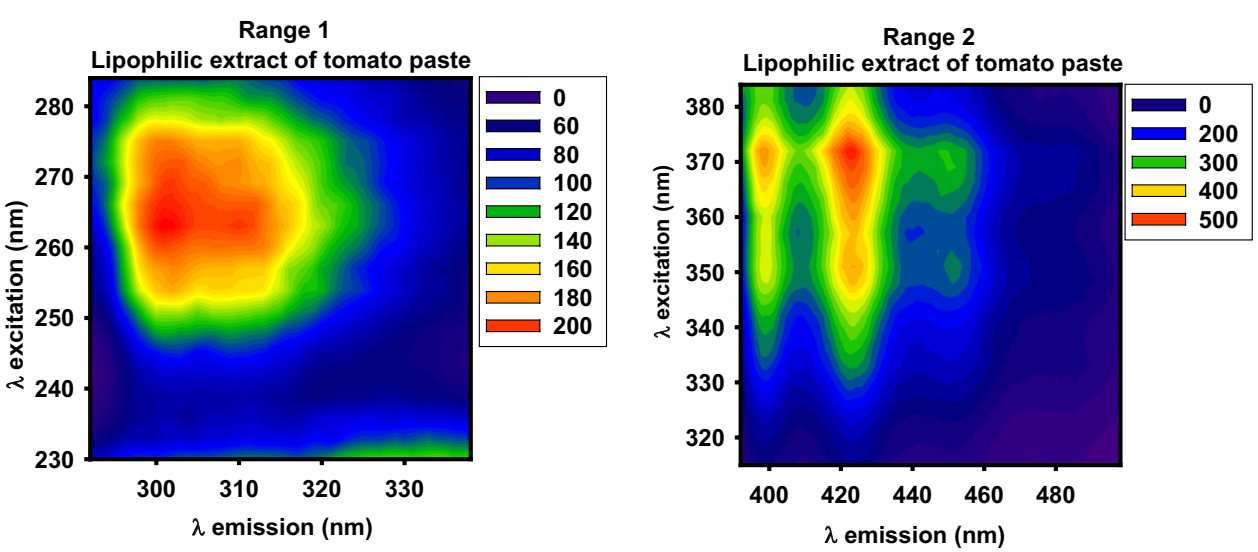
at 350 and 370 for excitation and maxima at 400, 425, and $450 \mathrm{~nm}$ for emission were found. These regions might be also related with flavonoids. In both cases, the EEMs suggest a mix of compounds. Although the presence of carotenoids is not ruled out, from studies by Lai et al. (2007) for tomato skin pigment extracts in methanol, no evidences were found of any lycopene fluorescence peak in the recorded EEMs. Other authors were also unable to find any lycopene fluorescence peaks (Konagaya et al. 2020), even when compared a lycopene standard with tomato extract (Adília Lemos et al. 2015).

When PARAFAC was applied to the samples in the different ranges, first step was to select the optimal number of components to explain the main variance of data. To select the optimal number of components the core consistency criteria was used (Bro and Kiers 2003). Hence, the core value is evaluated when the number of components increases until, at a certain point, the core consistency value decreases suddenly below $50 \%$, indicating that the optimal component number is the immediately before the one that causes this change. In this case, the optimal number of components was found to be three. The loadings and scores for the different components were obtained and loadings are shown in Fig. 5. The color intensity is proportional to score value and different for each of the components, as shown in the legend to the right of each image. As observed, there are not huge differences when the decomposition of samples was performed. In both ranges, first component presents mainly the same shape that the original EEMs.

Scores obtained for each component and a combination of them were related with total polyphenols (mg GAE/100 g) and antioxidant activity ( $\mu$ molTrolox/g). Regarding to polyphenols content, better correlation was found in the case of first range, where the sum of scores and total polyphenols, measured as mg GAE/100 g tomato paste, offered a correlation $(r)$ of 0.826 . Also, good correlation was found in the second range between the sum of scores and total polyphenols $(r=0.727)$. These results are in accordance with expected since these signals were attributed mainly to polyphenols content. In accordance with previous studies by other authors, the fluorescence profiles of these components might correspond with the presence of flavonoids (quercetin, catechin, epicatechin...) and anthocyanins (pelargonidine chloride) (Lai et al. 2007; Orzel et al. 2015).

In the case of antioxidant activity, only a good correlation was found between score of the second component in the range 2 and the $\mu \mathrm{mol}$ Trolox/g tomato paste $(r=0.80)$. However, this correlation is a bit uncertain due to the large peaks observed for this component. The lipophilic extract is mainly formed by carotenoid compounds ( $\beta$-carotene, $\gamma$-carotene...) (Jurado Capel 2012; Lai et al. 2007), which are more soluble in organic solvents, however, carotenoids do not exhibit intense fluorescence signal. This might explain the low correlation in this range.

Otherwise, tomato hydrophilic extracts were evaluated. Samples were prepared as described in the Materials and methods section, and EEMs were collected in two different ranges shown in Fig. 6. As observed, in the first range, the main fluorescence signals appear at 220 and $280 \mathrm{~nm}$ for excitation and $360 \mathrm{~nm}$ for emission. This region might be related with polyphenols as gallic acid among others. This region also presents more intense signal compared with second range. Second range exhibits a maximum signal nonwell-defined, as in the first range, around $325 / 430 \mathrm{~nm}$ for excitation/emission, respectively.

In this case, PARAFAC was also applied, and the optimal number of components was three in both ranges. Loadings for components in each range are shown in the Fig. 7. Scores were correlated with total polyphenols and antioxidant activity. As for lipophilic extracts, better correlations were found in the case of first range, where the sum of scores for component 1 and 3 and total polyphenols measured as
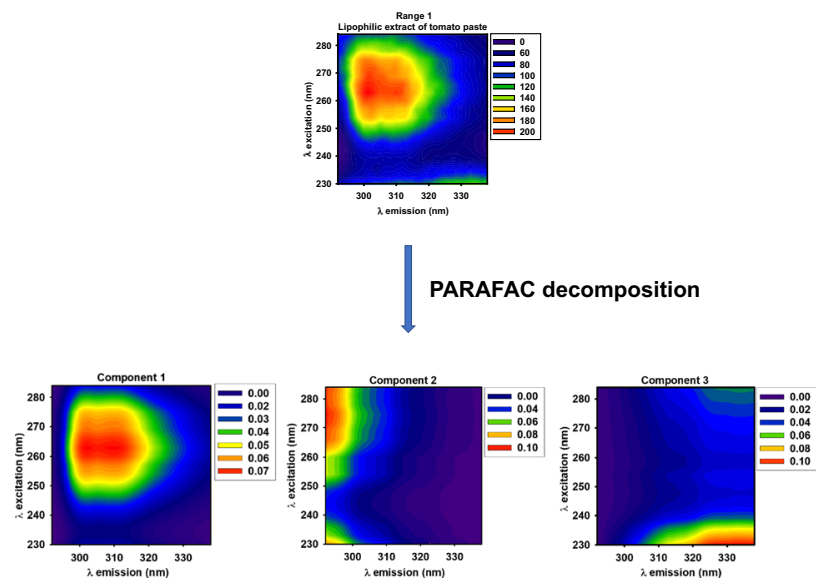



PARAFAC decomposition
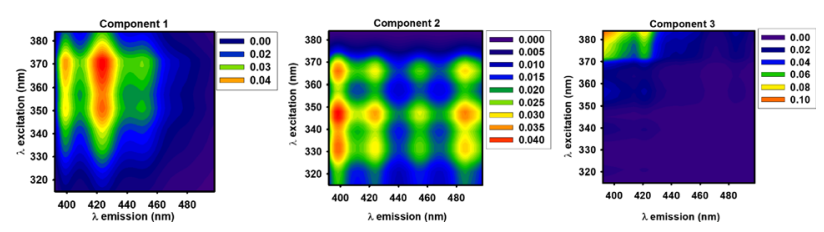

Fig. 5 Contour plots of the different components obtained by PARAFAC decomposition for the group of lipophilic extracts 
Fig. 6 EEMs of an hydrophilic extract in the two different ranges studied. Range 1 (left): excitation from 210 to $300 \mathrm{~nm}$ and emission from 310 to $390 \mathrm{~nm}$ and range 2 (right): excitation from 295 to $350 \mathrm{~nm}$ and emission from 380 to $480 \mathrm{~nm}$
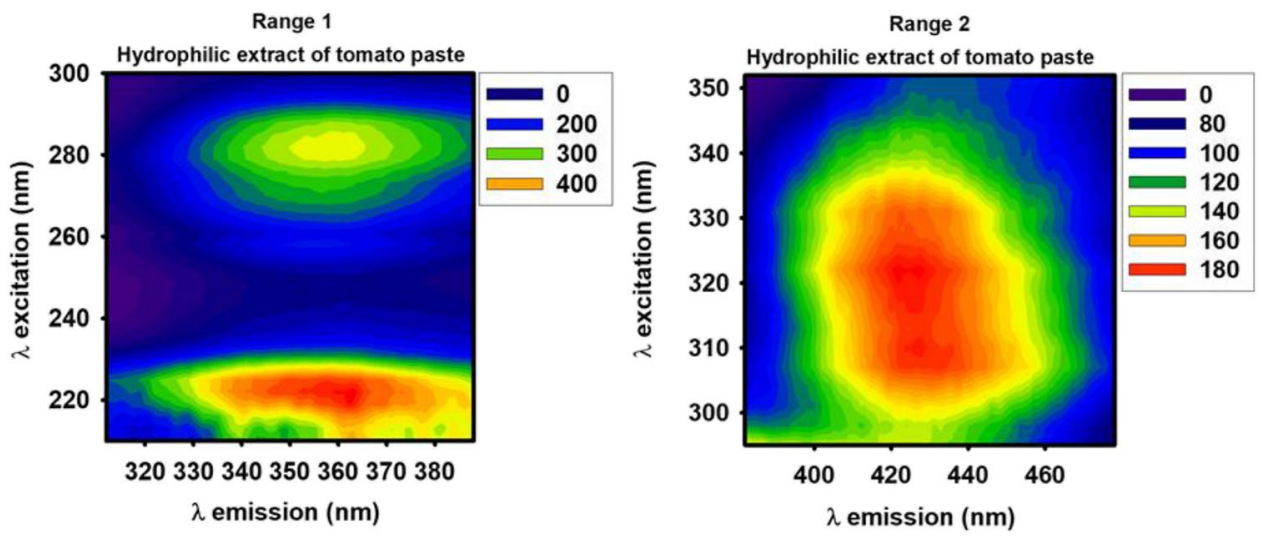

mg GAE/100 g tomato paste offered a correlation $(r)$ of 0.731 while the scores for component 3 and total polyphenols offered a correlation of 0.744 . In the second range, also good correlation was found for total polyphenols and scores for first component $(r=0.790)$. This component presents a similar shape described for flavonoids by other authors (Lai et al. 2007). As expected, these ranges are attributed to total polyphenols, mainly extracted in the hydrophilic extracts. However, in the case of Trolox content ( $\mu$ mol Trolox/g tomato paste), poor correlations were found for all combination of scores values assayed.

The obtained results point to the polyphenolic compounds as the main antioxidant compounds responsible of fluorescent signals in both the hydrophilic and lipophilic extracts of tomato paste. It would be interesting to perform a comparative study with the raw tomato utilized to check if there is a loss of antioxidant compounds during preparation of tomato paste samples. Other possibility is that some of the lipophilic antioxidants that could exhibit fluorescence be in a conjugate non-fluorescent form.
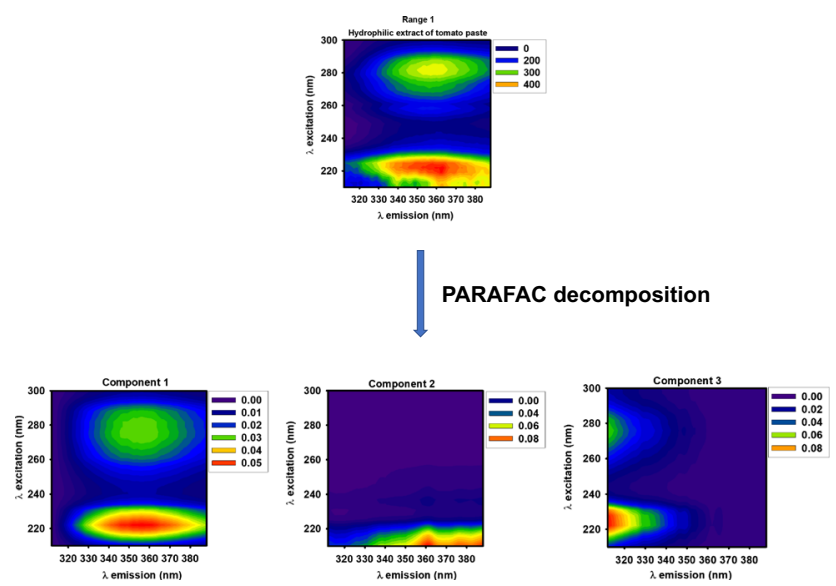

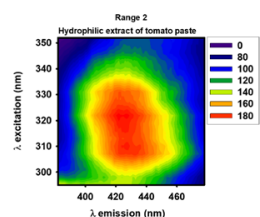

PARAFAC decomposition
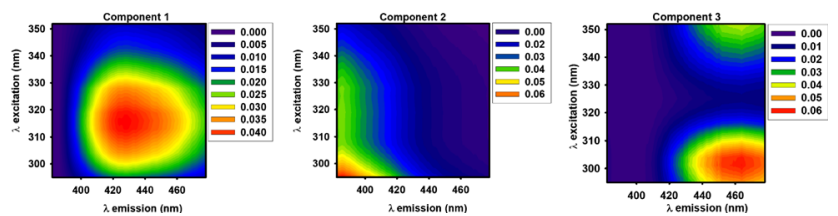

Fig. 7 Contour plots of the different components obtained by PARAFAC decomposition for the group of hydrophilic extracts 
hydrophilic and lipophilic antioxidant activity measured by the spectrophotometric assays.

Supplementary Information The online version contains supplementary material available at https://doi.org/10.1007/s12161-021-02175-1.

Funding Open Access funding provided thanks to the CRUE-CSIC agreement with Springer Nature. This study was funded by by the Ministerio de Ciencia e Innovación of Spain (Project PID2020112996 GB-100) and Consejería de Economía, Hacienda y Agenda Digital, Junta of Extremadura (Project IB20016), co-financed by the Fondo Europeo de Desarrollo Regional.

\section{Declarations}

Ethics Approval This article does not contain any studies with human participants or animals performed by any of the authors.

Consent to Participate Not applicable.

Conflict of Interest Olga Monago-Maraña declares that she has no conflict of interest. Teresa Galeano-Díaz declares that she has no conflict of interest. Rosario Pardo-Botello declares that she has no conflict of interest. Fátima Chamizo-Calero declares that she has no conflict of interest. Olga Monago-Maraña declares that she has no conflict of interest. Raquel Rodríguez-Corchado declares that she has no conflict of interest. Rosa de la Torre-Carreras declares that she has no conflict of interest. Teresa Galeano-Díaz declares that she has no conflict of interest.

Open Access This article is licensed under a Creative Commons Attribution 4.0 International License, which permits use, sharing, adaptation, distribution and reproduction in any medium or format, as long as you give appropriate credit to the original author(s) and the source, provide a link to the Creative Commons licence, and indicate if changes were made. The images or other third party material in this article are included in the article's Creative Commons licence, unless indicated otherwise in a credit line to the material. If material is not included in the article's Creative Commons licence and your intended use is not permitted by statutory regulation or exceeds the permitted use, you will need to obtain permission directly from the copyright holder. To view a copy of this licence, visit http://creativecommons.org/licenses/by/4.0/.

\section{References}

Adília Lemos M, Sárniková K, Bot F et al (2015) Use of time-resolved fluorescence to monitor bioactive compounds in plant based foodstuffs. Biosensors 5:367-397. https://doi.org/10.3390/bios5 030367

Anaya JPR 2013) Influencia de las técnicas culinarias sobre el contenido de polifenoles y capacidad antioxidante en hortalizas de la dieta mediterránea. Granada

Bro R (1997) PARAFAC. Tutorial and applications. Chemom Intell Lab Syst 38:149-171

Bro R, Kiers HAL (2003) A new efficient method for determining the number of components in PARAFAC models. J Chemom 17:74286. https://doi.org/10.1002/cem.801

Canene-Adams K, Campbell J K, Zaripheh S et al (2005) The tomato as a functional food. American Society for Nutritional Sciences $1226-1230$.
Capanoglu E, Beekwilder J, Boyacioglu D et al (2008) Changes in Antioxidant and Metabolite Profiles during Production of Tomato Paste. J Agric Food Chem 56:964-973

Capanoglu E, Beekwilder J, Boyacioglu D et al (2010) The effect of industrial food processing on potentially health-beneficial tomato antioxidants. Crit Rev Food Sci Nutr 50:919-930. https://doi.org/ 10.1080/10408390903001503

Espinosa-Mansilla E, Muñoz de la Peña A. González Gómez D (2005) Chemical Educator 10:1-9. https://doi.org/10.1333/s008970509 $33 \mathrm{a}$

García-Alonso FJ, Navarro-González I, Ros G et al (2015) Assessment of the antioxidant properties of tomato extracts: A synergistic approach using in vitro chemical tests and cell-based assays. Acta Aliment 44:297-303. https://doi.org/10.1556/066.2015.44.0006

George B, Kaur C, Khurdiya DS et al (2004) Antioxidants in tomato (Lycopersium esculentum) as a function of genotype. Food Chem 84:45-51. https://doi.org/10.1016/S0308-8146(03)00165-1

Gümüşay ÖA, Borazan AA, Ercal N et al (2015) Drying effects on the antioxidant properties of tomatoes and ginger. Food Chem 173:156-162. https://doi.org/10.1016/j.foodchem.2014.09.162

Hassoun A, Sahar A, Lakhal L et al (2019) Fluorescence spectroscopy as a rapid and non-destructive method for monitoring quality and authenticity of fish and meat products: Impact of different preservation conditions. LWT 103:279-292. https://doi.org/10.1016/j. lwt.2019.01.021

Jacob K, García-Alonso FJ, Ros G, Periago MJ (2010) Stability of carotenoids, phenolic compounds, ascorbic acid and antioxidant capacity of tomatoes during thermal processing. Archivos Latinoamericanos de Nutrición (ALAN), 60:192-198. http://www. alanrevista.org/ediciones/2010/2/art-13/

Jurado Capel L (2012) Máster en ciencias analíticas y bioanalíticas. https://digibuo.uniovi.es/dspace/bitstream/handle/10651/4196/ TFM_LauraJuradoCapel.pdf?sequence $=6 \&$ is Allowed $=\mathrm{y}$

Koh E, Charoenprasert S, Mitchell AE (2012) Effects of industrial tomato paste processing on ascorbic acid, flavonoids and carotenoids and their stability over one-year storage. J Sci Food Agric 92:23-28. https://doi.org/10.1002/jsfa.4580

Konagaya K, Al Riza DF, Nie S et al (2020) Monitoring mature tomato (red stage) quality during storage using ultraviolet-induced visible fluorescence image. Postharvest Biol Technol 160:111031. https:// doi.org/10.1016/j.postharvbio.2019.111031

Lai A, Santangelo E, Soressi GP, Fantoni R (2007) Analysis of the main secondary metabolites produced in tomato (Lycopersicon esculentum, Mill.) epicarp tissue during fruit ripening using fluorescence techniques. Postharvest Biol Technol 43:335-342. https://doi.org/10.1016/j.postharvbio.2006.09.016

Lei T, Sun DW (2019) Developments of nondestructive techniques for evaluating quality attributes of cheeses: A review. Trends Food Sci Technol 88:527-542. https://doi.org/10.1016/j.tifs.2019.04.013

Lenucci MS, Cadinu D, Taurino M, Piro G et al (2006) Antioxidant composition in cherry and high-pigment tomato cultivars. J Agric Food Chem 54:2606-2613. https://doi.org/10.1021/jf052920c

Martí R (2018). Metodologías para la evaluación del contenido en polifenoles en tomate aplicadas al estudio del efecto del genotipo y de estrategias de cultivo respetuosas con el medio ambiente. https://www.tesisenred.net/bitstream/handle/10803/461096/2018_ Tesis_Marti Renau_Raul.pdf?sequence $=1 \&$ isAllowed=y

Martínez-Valverde I, Periago MJI, Chesson A, Provan G (2002) Phenolic compounds, lycopene and antioxidant activity in commercial varieties of tomato (Lycopersicum esculentum). J Sci Food Agric 82:323-330. https://doi.org/10.1002/jsfa.1035

Mediterranean diet (2013). https://ich.unesco.org/en/decisions/8. $\mathrm{COM} / 8.10$

Miller NJ, Rice-Evans CA (1997) Factors influencing the antioxidant activity determined by the ABTS.+ radical cation assay. Free 
Radical Res 26:195-199. https://doi.org/10.3109/1071576970 9097799

Moharram HA, Youssef MM (2014) Methods for Determining the Antioxidant Activity : A Review. Alex J Food Sci Technol 11:3141. https://doi.org/10.12816/0025348

Olivieri AC, Escandar GM (2014) Practical Three-Way Calibration. Elsevier

Olivieri AC, Wu HL, Yu RQ (2009) MVC2: A MATLAB graphical interface toolbox for second-order multivariate calibration. Chemom Intell Lab Syst 96:246-251. https://doi.org/10.1016/j. chemolab.2009.02.005

Orzel J, Stanimirova I, Czarnik-Matusewicz B et al (2015) Prediction of the hydrophilic antioxidant capacity of tomato pastes from the IR and fluorescence excitation-emission spectra of extracts and intact samples. Talanta 138:64-70. https://doi.org/10.1016/j.talan ta.2015.01.026

Pérez-Jiménez J, Arranz S, Tabernero M, Díaz-Rubio ME et al (2008) Updated methodology to determine antioxidant capacity in plant foods, oils and beverages: Extraction, measurement and expression of results. Food Res Int 41:274-285. https://doi.org/10. 1016/j.foodres.2007.12.004

Pisoschi AM, Negulescu GP (2012) Methods for Total Antioxidant Activity Determination: A Review. Biochemistry and Analytical Biochemistry 1:1-10. https://doi.org/10.4172/2161-1009.1000106

Pisoschi AM, Pop A, Cimpeanu C et al (2016) Antioxidant capacity determination in plants and plant-derived products: A review. Oxid Med Cell Longev 2016:9130976. https://doi.org/10.1155/ 2016/9130976

Prior RL, Hoang H, Gu L et al (2003) Assays for hydrophilic and lipophilic antioxidant capacity (oxygen radical absorbance capacity (ORACFL)) of plasma and other biological and food samples. J Agric Food Chem 51:3273-3279. https://doi.org/10.1021/jf026 2256

Prior RL, Wu X, Schaich K (2005) Standardized methods for the determination of antioxidant capacity and phenolics in foods and dietary supplements. J Agric Food Chem 53:4290-4302. https:// doi.org/10.1021/jf0502698

Romero A, Olives A, Martín M, Del Castillo B et al (2002) Estudio del efecto solvatocrómico en derivados fenólicos naturales Study of the solvatochromic effect on natural phenolic compounds. ARS Pharmaceutica 43:57-71. http://bit.ly/1sqn263
Sahlin E, Savage GP, Lister CE (2004) Investigation of the antioxidant properties of tomatoes after processing. J Food Compos Anal 17:635-647. https://doi.org/10.1016/j.jfca.2003.10.003

Savatović S, Ćetković G, Čanadanović-Brunet J et al (2012) Tomato waste: A potential source of hydrophilic antioxidants. Int J Food Sci Nutr 63:129-137. https://doi.org/10.3109/09637486.2011. 606211

Shaikh S, O'Donnell C (2017) Applications of fluorescence spectroscopy in dairy processing: a review. Curr Opin Food Sci 17:16-24. https://doi.org/10.1016/j.cofs.2017.08.004

Sofi F, Abbate R, Gensini G et al (2010) Accruing evidence on benefits of adherence to the Mediterranean diet on health: An updated systematic review and meta-analysis. Am J Clin Nutr 92:1189-1196. https://doi.org/10.3945/ajcn.2010.29673

Toor RK, Savage GP (2005) Antioxidant activity in different fractions of tomatoes. Food Res Int 38:487-494. https://doi.org/10.1016/j. foodres.2004.10.016

Trichopoulou A, Martínez-González MA, Tong TYN et al (2014) Definitions and potential health benefits of the Mediterranean diet: Views from experts around the world. BMC Med 12:1-6. https:// doi.org/10.1186/1741-7015-12-112

Vallverdú-Queralt A, Medina-Remón A, Martínez-Huélamo M et al (2011) Phenolic profile and hydrophilic antioxidant capacity as chemotaxonomic markers of tomato varieties. J Agric Food Chem 59:3994-4001. https://doi.org/10.1021/jf104400g

Wu X, Beecher GR, Holden JM et al (2004) Lipophilic and hydrophilic antioxidant capacities of common foods in the United States. J Agric Food Chem 52:4026-4037. https://doi.org/10.1021/jf049 $696 \mathrm{w}$

Zanfini A, Franchi GG, Massarelli P et al (2017) Phenolic compounds, carotenoids and antioxidant activity in five tomato (lycopersicon esculentum mill.) cultivars. Ital J Food Sci 29:90-99

Publisher's Note Springer Nature remains neutral with regard to jurisdictional claims in published maps and institutional affiliations. 